\title{
Toward a Combinatorial Approach for the Prediction of IgG Half-Life and Clearance ${ }^{\mathrm{S}}$
}

\author{
Dennis R. Goulet, Michael J. Watson, Susan H. Tam, Adam Zwolak, Mark L. Chiu, \\ William M. Atkins, and Abhinav Nath
}

\begin{abstract}
Department of Medicinal Chemistry, University of Washington, Seattle, Washington (D.R.G., M.J.W., W.M.A., A.N.); and Biologics Research, Janssen Research and Development, LLC, Spring House, Pennsylvania (S.H.T., A.Z., M.L.C.)
\end{abstract}

Received April 6, 2018; accepted September 10, 2018

\begin{abstract}
The serum half-life and clearance of therapeutic monoclonal antibodies (mAbs) are critical factors that impact their efficacy and optimal dosing regimen. The $\mathrm{pH}$-dependent binding of an $\mathrm{mAb}$ to the neonatal Fc receptor ( $\mathrm{FcRn}$ ) has long been recognized as an important determinant of its pharmacokinetics. However, FcRn affinity alone is not a reliable predictor of $\mathrm{mAb}$ half-life, suggesting that other biologic or biophysical mechanisms must be accounted for. mAb thermal stability, which reflects its unfolding and aggregation propensities, may also relate to its pharmacokinetic properties. However, no rigorous statistical regression methods have been used to identify combinations of physical parameters that best predict biologic properties. In this work, a panel of eight mAbs with published human pharmacokinetic data were selected for biophysical analyses of FcRn binding and thermal stability. Biolayer
\end{abstract}

interferometry was used to characterize $\mathrm{FcRn} / \mathrm{mAb}$ binding at acidic and neutral $\mathrm{pH}$, while differential scanning calorimetry was used to determine thermodynamic unfolding parameters. Individual binding or stability parameters were generally weakly correlated with half-life and clearance values. Least absolute shrinkage and selection operator regression was used to identify the combination of two parameters with the best correlation to half-life and clearance as being the FcRn binding response at pH 7.0 and the change in heat capacity. Leave-one-out subsampling yielded a root mean square difference between observed and predicted halflife of just 2.7 days (16\%). Thus, the incorporation of multiple biophysical parameters into a cohesive model may facilitate earlystage prediction of in vivo half-life and clearance based on simple in vitro experiments.

\section{Introduction}

Monoclonal antibodies (mAbs) are an important class of drugs that have proven invaluable for the treatment of cancer, autoimmune disease, and other indications. In 2017, 10 mAb-based drugs were approved by the US Food and Drug Administration (FDA), and over 50 mAbs were in late-stage clinical trials (Kaplon and Reichert, 2018). The ability to design a wide range of agonistic or antagonistic drugs that target any soluble or cell-surface antigen, while conserving a well-defined protein scaffold, makes mAbs extremely attractive as therapeutic agents. Engineered mAb-based molecules such as bispecific antibodies and antibody-drug conjugates have introduced novel mechanisms for the treatment of disease (Spiess et al., 2015; Beck et al., 2017).

One reason for the success of mAb therapeutics, particularly of the IgG class, is their slow elimination kinetics. The serum stability of IgG mAbs makes intravenous or subcutaneous administration a

This work was supported by the University of Washington Department of Medicinal Chemistry; the University of Washington SOP Faculty Innovation Fund; and the National Institute of General Medical Sciences of the National Institutes of Health [Grant T32GM007750]. The content is solely the responsibility of the authors and does not necessarily represent the official views of the National Institutes of Health.

https://doi.org/10.1124/dmd.118.081893.

S This article has supplemental material available at dmd.aspetjournals.org. feasible approach, as drug can be delivered with a dosing interval of several weeks. The biologic mechanism for the slow clearance of IgGs relies on escape from lysosomal degradation by binding to the neonatal crystallizable fragment $(\mathrm{Fc})$ receptor $(\mathrm{FcRn})$ via the $\mathrm{Fc}$ of the mAb constant region (Roopenian et al., 2003; Roopenian and Akilesh, 2007). When serum proteins are pinocytosed by endothelial cells for lysosomal proteolysis, the acidic $\mathrm{pH}$ of the endosome $(\mathrm{pH}<6.5)$ allows IgG mAbs to bind FcRn located in the endosomal membrane. The complex is then trafficked back to the cell surface, where mAbs are released at the neutral $\mathrm{pH}(\mathrm{pH}$ 7.4) of the blood. Thus, the importance of $\mathrm{pH}$-dependent FcRn binding has long been recognized as an important determinant of IgG half-life (Raghavan et al., 1995).

Although mAbs have an average elimination half-life of several weeks in humans, there is a large variability associated with this parameter. It is not uncommon for IgG mAbs to have half-lives as short as 1 week or as long as 4 weeks (Suzuki et al., 2010; Tam et al., 2013). Mutation of the FcRn binding interface can further broaden the range of IgG clearance parameters (Robbie et al., 2013). Part of the variation in IgG half-life can be attributed to target-dependent effects, such as receptor-mediated internalization and degradation (Wang et al., 2008). However, even mAbs that target soluble antigens and lack receptormediated clearance have a wide range of elimination kinetics. A consequence of this variation is the investment in $\mathrm{mAb}$ candidates that

ABBREVIATIONS: BLI, biolayer interferometry; $\Delta \mathrm{C}_{\mathrm{P}}$, change in heat capacity upon unfolding; $\Delta \mathrm{H}$, change in enthalpy of unfolding; $\mathrm{DSC}$, differential scanning calorimetry; Fc, crystallizable fragment; FcRn, neonatal crystallizable fragment receptor; FDA, Food and Drug Administration; $k_{a}$, kinetic association rate constant; $\mathrm{k}_{\mathrm{d}}$, kinetic dissociation rate constant; LASSO, least absolute shrinkage and selection operator; mAb, monoclonal antibody; PBS, phosphate-buffered saline; PK, pharmacokinetics; RMSD, root mean square difference; $\mathrm{T}_{\mathrm{m}}$, melting temperature. 
have suboptimal pharmacokinetic (PK) parameters, which necessitates higher doses or more frequent dosing.

To increase the convenience and cost-effectiveness of mAb therapies, there is a need for predictive models that can accurately determine PK properties before candidates are investigated in animals or humans. Ideally, these models would be based on biophysical parameters that can be readily measured early in the drug pipeline (Dostalek et al., 2017; Avery et al., 2018). Historically, FcRn binding at endosomal and neutral $\mathrm{pH}$ have both been shown to affect $\mathrm{mAb}$ elimination, and accounting for the interaction at both $\mathrm{pH}$ values may provide more predictive success (Wang et al., 2011; Souders et al., 2015). Thermal stability, and related properties like aggregation propensity, may also affect half-life, although less is known about this possible relationship (Datta-Mannan et al., 2015a). Although these and other biophysical parameters, such as nonspecific binding or electrostatic interactions, may be predictively important (Datta-Mannan et al., 2015b; Tibbitts et al., 2016; Jain et al., 2017), their relative contributions and the underlying mechanistic relationships remain unclear.

In this work, we characterized the FcRn binding properties and thermal stability of a panel of IgG1 mAbs and, using the LASSO (least absolute shrinkage and selection operator) machine-learning technique (Tibshirani, 1996), identified the combination of parameters that best correlated with their half-life and clearance values from the literature. The most important parameters were then used to predict the half-life and clearance of each $\mathrm{mAb}$, revealing that just two biophysical determinants could be used to accurately predict human PK for this set of mAbs. Crucially, this empirical approach to the problem allows us to identify predictive parameters in an unbiased fashion and highlights correlations that could guide future mechanistic studies. Predictions could be further improved by refining this approach, perhaps by incorporating and testing some of the many other parameters that have been proposed to affect $\mathrm{mAb} \mathrm{PK}$.

\section{Materials and Methods}

Proteins. Clinical mAbs were obtained through clinical vendors by S.H.T. Size-exclusion chromatography and SDS-PAGE were performed to ensure the integrity of mAbs. Human FcRn with $\beta_{2}$-microglobulin (catalog \#CT009-H08H50) was purchased from Sino Biological (Wayne, PA). The presence of both the FcRn $\alpha$-chain and $\beta_{2}$-microglobulin was verified by SDS-PAGE.

Biolayer Interferometry. Kinetic experiments were performed at $25^{\circ} \mathrm{C}$ on an Octet RED384 (FortéBio, Fremont, CA) using 96-well half-area plates at $1000 \mathrm{rpm}$ and a total $100 \mu \mathrm{l} /$ well. First, $2.5 \mu \mathrm{g} / \mathrm{ml}$ His-tagged human FcRn in $1 \times$ phosphate-buffered saline (PBS), pH $7.2\left(8.10 \mathrm{mM} \mathrm{Na} \mathrm{HPO}_{4}, 1.47 \mathrm{mM}\right.$ $\mathrm{KH}_{2} \mathrm{PO}_{4}, 137 \mathrm{mM} \mathrm{NaCl}, 2.67 \mathrm{mM} \mathrm{KCl}$ ) was loaded onto Ni-NTA sensor tips for 300 seconds to obtain a response of $2 \mathrm{~nm}$. Two baseline steps were performed for 120 seconds and then 60 seconds by blocking with $1 \times$ PBS containing $1 \%$ casein (w/v) and $0.05 \%$ Tween 20 (v/v) brought to $\mathrm{pH} 6.0 \mathrm{or} \mathrm{pH} 7.0$ using $\mathrm{HCl}$. A 180 -second association phase was performed with $66.7,16.7,4.17$, and $1.04 \mathrm{nM}$ IgG at pH 6.0 or $6670,1670,417$, and $104 \mathrm{nM} \mathrm{IgG}$ at pH 7.0 (same buffer as in baseline steps). Dissociation was performed for 180 seconds in fresh buffer matching the baseline/association buffer.

Analysis was performed in Octet Data Analysis software version 7. Reference data (mAb binding to tips lacking FcRn) were subtracted from sample data. Association and dissociation data for a given $\mathrm{mAb}$ at $\mathrm{pH} 6.0$ were globally fit using the 1:1 model with a linked maximal response $\left(\mathrm{R}_{\max }\right)$ for the four concentrations. For $\mathrm{pH} 7.0$ data, none of the models produced adequate global fits, so the response at the highest $\operatorname{IgG}$ concentration $(6.67 \mu \mathrm{M})$ was used as a model-independent measure of $\mathrm{pH} 7.0$ binding.

Differential Scanning Calorimetry. Thermal unfolding experiments were performed on a MicroCal VP-Capillary differential scanning calorimetry (DSC) (Malvern Panalytical, Malvern, UK) using 0.15 or $0.5 \mathrm{mg} / \mathrm{ml} \mathrm{IgG} \mathrm{in} 1 \times \mathrm{PBS}$, $\mathrm{pH}$ 7.2. IgG samples and reference buffer were scanned from 40 to $100^{\circ} \mathrm{C}$ at $60^{\circ} \mathrm{C} / \mathrm{h}$. Three buffer/buffer scans were run between each sample/buffer scan. After subtracting the buffer/buffer scan immediately preceding the sample/buffer scan and normalizing concentration, "Progress Baseline" subtraction was performed to obtain a thermogram with a flat baseline using Origin 7 software. Thermodynamic parameters melting temperature $\left(\mathrm{T}_{\mathrm{m}}\right)$ and change in enthalpy of unfolding $(\Delta \mathrm{H})$ were obtained by fitting to a non-two-state model containing three peaks. The total $\Delta \mathrm{H}$ was calculated as the sum of individual $\Delta \mathrm{H}$ values. The weight-averaged $\mathrm{T}_{\mathrm{m}}$ was obtained using the $\mathrm{T}_{\mathrm{m}}$ and $\Delta \mathrm{H}$ from each peak according to the following equation:

$$
T_{m, a v g}=\frac{\sum_{i=1}^{3} T_{m, i} \cdot \Delta H_{i}}{\sum_{i=1}^{3} \Delta H_{i}}
$$

The change in heat capacity upon unfolding $\left(\Delta \mathrm{C}_{\mathrm{P}}\right)$ was determined by using the "Step at Half Area" baseline option and calculating the difference between baselines before and after the step. Using the "Step at Peak" option yielded essentially identical $\Delta \mathrm{C}_{\mathrm{P}}$ values $\left(R^{2}=0.998\right)$. DSC parameters presented are the average of two independent experiments (one at $0.15 \mathrm{mg} / \mathrm{ml}$ and one at $0.5 \mathrm{mg} / \mathrm{ml})$.

Regression Analysis. Literature reports of half-life and clearance were found by searching for a given antibody and "half-life" in PubMed (https://www.ncbi. nlm.nih.gov/pubmed) and selected based on a description of human clinical studies. FDA package inserts were used as additional references. Volumes of distribution at steady state for the various mAbs ranged within 2-fold $(0.060$ $0.106 \mathrm{l} / \mathrm{kg}$ ). All the studies either explicitly reported linear PK or did not specifically mention nonlinearity. When multiple doses or routes of administration were investigated, the average PK value of all conditions was used.

Analysis was performed in MATLAB (MathWorks, Natick, MA) R2017b using the "regress" and "lasso" functions. Prior to regression analysis, the six parameters $\left[\mathrm{FcRn}\right.$ kinetic association rate constant $\left(\mathrm{k}_{\mathrm{a}}\right)$ at $\mathrm{pH}$ 6.0, $\mathrm{FcRn}$ kinetic association rate constant $\left(\mathrm{k}_{\mathrm{d}}\right)$ at $\mathrm{pH} 6.0, \mathrm{FcRn}$ response at $\mathrm{pH} 7.0, \Delta \mathrm{H}, \mathrm{T}_{\mathrm{m}}$, and $\Delta \mathrm{C}_{\mathrm{P}}$ ] were tabulated with each column as a predictor and each row as a mAb. Parameters were normalized by subtracting the mean of the column and dividing by the S.D. of the column. Thus, the normalized columns all had a mean of 0 and an S.D. of 1, but retained their distribution of values for the different mAbs, ensuring that each parameter contributed equally to regression calculations. In linear regression, coefficients for each parameter are optimized so as to minimize the root mean square difference (RMSD) between observed and predicted values of a dependent variable (here, either half-life or clearance). LASSO involves a similar optimization, with the additional constraint that the sum of all the coefficients must be lower than a regularization parameter $\lambda$ (Tibshirani, 1996). Higher values of $\lambda$ favor simpler models with fewer nonzero coefficients, allowing us to rigorously explore the trade-off between model accuracy and model complexity.

After LASSO regression, models based on the optimal parameter pairs were calculated using the following equation:

$$
y=m_{1} \cdot x_{1}+m_{2} \cdot x_{2}+b
$$

where $y$ is the two-parameter score, $x_{1}$ and $x_{2}$ are the parameter values (e.g., FcRn-IgG response at $\mathrm{pH} 7.0$ and $\left.\Delta \mathrm{C}_{\mathrm{P}}\right), m_{1}$ and $m_{2}$ are the best-fit regression coefficients, and $b$ is the regression intercept. For leave-one-out analysis, the halflife of each $\mathrm{mAb}$ in turn was predicted by performing a regression with the other seven $\mathrm{mAbs}$, and then using the resulting intercept and coefficients along with the parameter values of the mAb to calculate its two-parameter score.

\section{Results}

To determine the relation between biophysical parameters of therapeutic mAbs and their PK characteristics, a small selection of mAbs with existing human half-life data were required. Eight clinical IgG $1 \kappa$ mAbs targeting soluble antigens were selected based on FDA package inserts and clinical trials describing half-lives ranging from 7.2 to 24.5 days (Table 1 ). These half-life values, and separately the mAb clearance values, were used as the dependent variables to which the independent variables (biophysical parameters) would be correlated.

Since FcRn is known to salvage $\mathrm{IgG}$ from lysosomal degradation and thus affect serum stability, the affinity of these eight mAbs for FcRn was examined as one potential determinant of half-life and clearance. In 
particular, both the $\mathrm{k}_{\mathrm{a}}$ and $\mathrm{k}_{\mathrm{d}}$ values of the interaction at endosomal $\mathrm{pH}$ ( $\mathrm{pH}$ 6.0) were determined by biolayer interferometry (BLI) because both kinetic parameters could be important predictors. The kinetic data fit well to the simplest $1: 1$ binding model, from which $\mathrm{k}_{\mathrm{a}}$ and $\mathrm{k}_{\mathrm{d}}$ parameters were extracted for each mAb (Fig. 1A; Supplemental Fig. 1; Table 1). When the IgG-FcRn $k_{a}$ and $k_{d}$ were compared with half-life and clearance, they unexpectedly revealed very weak correlations (Fig. 3, A and $\mathrm{B}$ ). This suggests that FcRn affinity at endosomal $\mathrm{pH}$ is not the most important determinant of half-life and clearance for IgG1 mAbs containing different variable regions.

IgG-FcRn binding is highly $\mathrm{pH}$ dependent, with tight binding occurring only below $\mathrm{pH} \sim 6.5$. For the FcRn salvage mechanism to be effective, an IgG must associate tightly with FcRn in the endosome; however, it also must be efficiently released from FcRn upon exposure to the neutral $\mathrm{pH}(\mathrm{pH}$ 7.4) of the blood. Thus, the binding kinetics of the mAbs to $\mathrm{FcRn}$ at neutral $\mathrm{pH}$ were considered as another possible determinant of serum half-life, as previously considered by others (Wang et al., 2011; Borrok et al., 2015). Well-defined binding was not observed at $\mathrm{pH} 7.4$, even with $>1 \mathrm{mg} / \mathrm{ml} \mathrm{IgG}$ binding to immobilized FcRn. Instead, binding and dissociation were examined at $\mathrm{pH} 7.0$, which was the highest $\mathrm{pH}$ with quantifiable binding. The $\mathrm{pH}$ 7.0 data did not fit well with any simple models such as $1: 1$ or bivalent analyte, preventing the determination of accurate $\mathrm{k}_{\mathrm{a}}$ and $\mathrm{k}_{\mathrm{d}}$ values. This complexity may result from avidity in IgG-FcRn interactions (Abdiche et al., 2015). As an alternative, the maximum response achieved was tabulated as an objective, model-independent measure of binding at pH 7.0 (Fig. 1B; Supplemental Fig. 2; Table 1). Comparison of these response values with $\mathrm{mAb}$ half-lives revealed an inverse correlation, indicating that long $\mathrm{mAb}$ half-life is associated with weak FcRn binding at neutral pH (Fig. 3C). Conversely, FcRn response at $\mathrm{pH} 7.0$ was positively correlated to clearance. Independent experiments confirmed the observed trends in FcRn binding at $\mathrm{pH} 6.0$ and 7.0 (Supplemental Figs. 3-5).

Thermal stability, which varies based on the amino acid sequence, is another biophysical property of mAbs that may affect half-life. DSC was used to monitor unfolding as a function of temperature. Since IgG unfolding thermograms have been shown to be similar at endosomal and neutral $\mathrm{pH}$, the experiments were performed only at pH 7.2 (Majumdar et al., 2015). After subtracting buffer scans and normalizing by concentration, the DSC data were fit to a non-two-state-state model with three components, which was the smallest number of components that accurately described each of the mAbs (Fig. 2A; Supplemental Figs. 6 and 7). From these fits, the total $\Delta \mathrm{H}$ (sum of the $\Delta \mathrm{H}$ values for each component) was tabulated, and revealed a weak negative correlation with half-life and a weak positive correlation with clearance (Fig. 3D; Table 1). The weight-averaged $T_{m}$ was also calculated as the $T_{m}$ of each fit component multiplied by the contribution of that component to the total $\Delta \mathrm{H}$. This $\mathrm{T}_{\mathrm{m}}$ parameter showed a weak positive correlation with half-life and a weak negative correlation with clearance (Fig. $3 \mathrm{E}$; Table 1). As a final predictor of half-life from DSC data, the difference in heat capacity between folded and unfolded states $\left(\Delta \mathrm{C}_{\mathrm{P}}\right)$ was calculated for each $\mathrm{mAb} . \Delta \mathrm{C}_{\mathrm{P}}$ was inversely correlated with half-life and positively correlated with clearance (Fig. 2B; Fig. 3F; Supplemental Fig. 8; Table 1).

Comparing individual BLI or DSC parameters yielded generally weak correlations with half-life and clearance with $R^{2}<0.8$. Multiple regression was performed with all six parameters and yielded very

TABLE 1

Literature PKs and biophysical parameters for clinical mAbs

\begin{tabular}{|c|c|c|c|c|c|c|c|c|}
\hline \multirow{2}{*}{ Antibody } & Human Half-Life & Human Clearance & $\mathrm{FcRn} \mathrm{k}_{\mathrm{a}}, \mathrm{pH} 6.0$ & $\mathrm{FcRn} \mathrm{k}_{\mathrm{d}}, \mathrm{pH} 6.0$ & FcRn Response, pH 7.0 & $\Delta \mathrm{H}$ & Weight Average $T_{m}$ & $\Delta \mathrm{C}_{\mathrm{P}}$ \\
\hline & $\mathrm{d}$ & $\mathrm{ml} /$ day per kilogram & $\mathrm{mM}^{-1} \mathrm{~s}^{-1}$ & $\mathrm{ks}^{-1}$ & $\mathrm{~nm}$ & $\mathrm{kcal} / \mathrm{mol}$ & ${ }^{\circ} \mathrm{C}$ & $\mathrm{kcal} / \mathrm{mol}$ per degree celsius \\
\hline Adalimumab $^{a-c}$ & $14.5 \pm 2.7$ & $4.2 \pm 0.9$ & $641 \pm 1$ & $1.59 \pm 0.01$ & 1.77 & $948 \pm 1$ & $73.9 \pm 0.1$ & $11.9 \pm 1.1$ \\
\hline Bevacizumab $^{d-g}$ & $19.7 \pm 0.4$ & $3.0 \pm 0.3$ & $349 \pm 0$ & $0.96 \pm 0.00$ & 1.89 & $709 \pm 69$ & $72.6 \pm 0.2$ & $6.7 \pm 2.3$ \\
\hline Carlumab $^{h, i}$ & $7.2 \pm 0.4$ & 13.2 & $437 \pm 1$ & $3.09 \pm 0.01$ & 1.97 & $884 \pm 133$ & $71.8 \pm 0.2$ & $21.1 \pm 3.7$ \\
\hline Golimumab $^{j-o}$ & $12.4 \pm 1.1$ & $10.9 \pm 4.0$ & $459 \pm 1$ & $1.56 \pm 0.00$ & 2.05 & $854 \pm 98$ & $75.0 \pm 0.1$ & $18.3 \pm 2.5$ \\
\hline Infliximab $^{p-t}$ & $12.1 \pm 4.0$ & $5.1 \pm 0.7$ & $423 \pm 0$ & $0.91 \pm 0.00$ & 1.96 & $843 \pm 26$ & $71.2 \pm 0.1$ & $12.4 \pm 1.7$ \\
\hline Omalizumab $^{u, v}$ & $24.5 \pm 2.1$ & $2.4 \pm 0.1$ & $371 \pm 0$ & $1.64 \pm 0.00$ & 0.72 & $932 \pm 55$ & $78.5 \pm 0.2$ & $13.6 \pm 2.2$ \\
\hline Siltuximab $^{w, x}$ & $19.9 \pm 1.0$ & $3.8 \pm 0.7$ & $505 \pm 1$ & $2.27 \pm 0.01$ & 1.10 & $706 \pm 11$ & $71.5 \pm 0.1$ & $13.5 \pm 0.6$ \\
\hline Ustekinumab $^{y, z}$ & $24.2 \pm 3.3$ & 2.9 & $535 \pm 1$ & $2.38 \pm 0.01$ & 1.10 & $738 \pm 45$ & $73.1 \pm 0.4$ & $11.6 \pm 3.9$ \\
\hline
\end{tabular}

${ }^{a}$ https://www.accessdata.fda.gov/drugsatfda_docs/label/2017/125057s399lbl.pdf.

${ }^{b}$ Weisman et al. (2003).

${ }^{c}$ den Broeder et al. (2002).

${ }^{d}$ https://www.accessdata.fda.gov/drugsatfda_docs/label/2016/125085s317lbl.pdf.

${ }^{e}$ Han et al. (2016).

${ }^{{ }^{f} \mathrm{Li}}$ et al. (2013).

${ }^{g} \mathrm{Lu}$ et al. (2008).

${ }^{h}$ https://ncats.nih.gov/files/CNTO-888.pdf.

${ }^{i}$ Sandhu et al. (2013).

${ }^{j}$ https://www.accessdata.fda.gov/drugsatfda_docs/label/2015/125433s014lbl.pdf.

${ }^{k}$ Zhuang et al. (2012).

'Zhuang et al. (2013).

${ }^{m}$ Ling et al. (2010).

${ }^{n} \mathrm{Xu}$ et al. (2010).

${ }^{\circ}$ Zhou et al. (2007).

${ }^{p}$ https://www.accessdata.fda.gov/drugsatfda_docs/label/2013/103772s5359lbl.pdf.

${ }^{q}$ Dotan et al. (2014).

${ }^{r}$ Fasanmade et al. (2011)

${ }^{s}$ Cornillie et al. (2001).

${ }^{t}$ Ternant et al., 2008.

${ }^{u}$ https://www.accessdata.fda.gov/drugsatfda_docs/label/2016/103976s5225lbl.pdf.

${ }^{v}$ Hayashi et al. (2007).

whttps://www.accessdata.fda.gov/drugsatfda_docs/label/2014/125496s000lbl.pdf.

${ }^{x}$ Kurzrock et al. (2013).

https://www.accessdata.fda.gov/drugsatfda_docs/label/2016/761044lbl.pdf

${ }^{z}$ Zhu et al. (2013). 
A

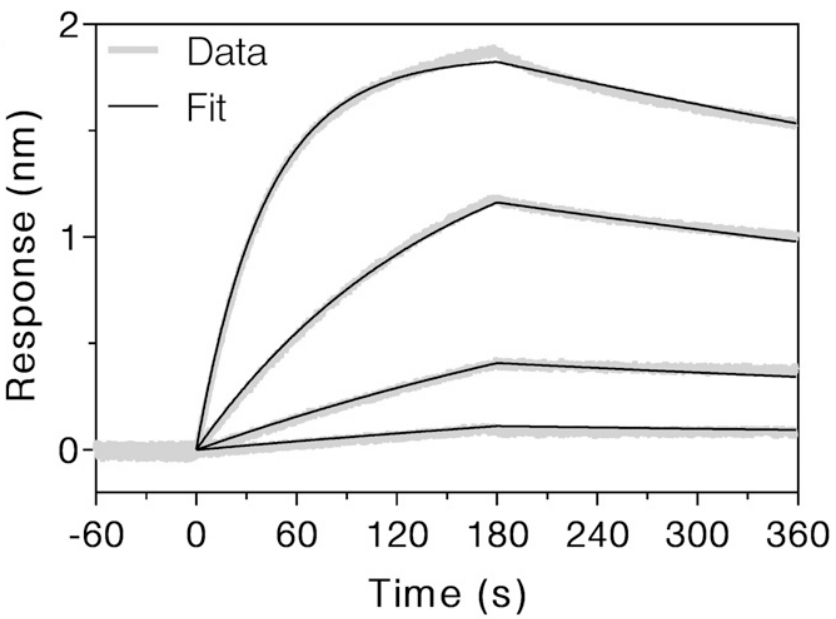

B

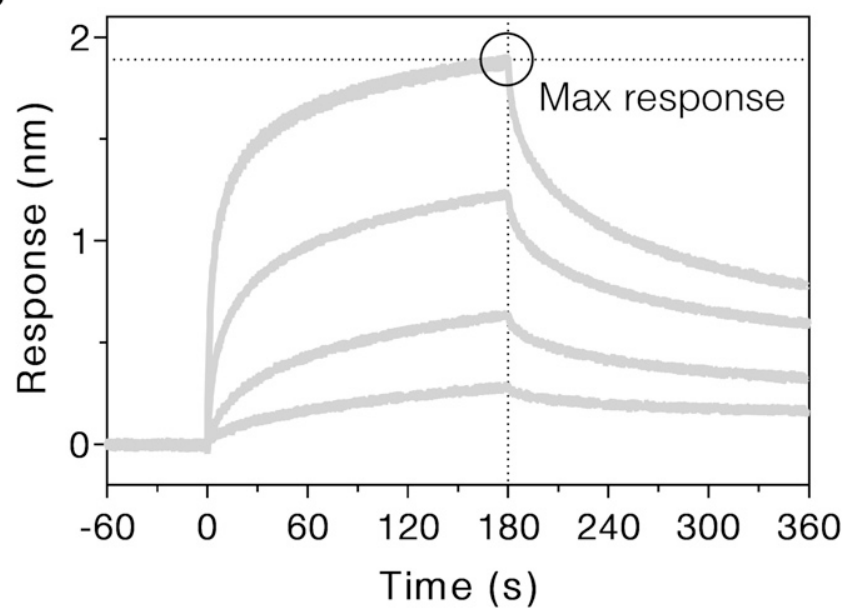

Fig. 1. BLI sensorgrams of bevacizumab binding to immobilized human FcRn at pH 6.0 (A) and 7.0 (B). At pH 6.0, Ni-NTA tips loaded with FcRn were dipped in buffer containing $66.7,16.7,4.17$, or $1.04 \mathrm{nM}$ bevacizumab to observe the association phase for 3 minutes, followed by dipping in buffer lacking bevacizumab to observe the dissociation phase for 3 minutes. Thick gray lines show the data, and narrow black lines show a global fit of all four concentrations to a 1:1 binding model, which yielded kinetic parameters $\mathrm{k}_{\mathrm{a}}$ and $\mathrm{k}_{\mathrm{d}}$. At $\mathrm{pH}$ 7.0, Ni-NTA tips loaded with FcRn were dipped in buffer containing 6670, 1670, 417, or $104 \mathrm{nM}$ bevacizumab to observe the association phase for 3 minutes, followed by dipping in buffer lacking bevacizumab to observe the dissociation phase for 3 minutes. Thick gray lines show the data, and the black circle highlights the maximum binding response achieved for the $6.67 \mu \mathrm{M}$ concentration. FcRn binding data at $\mathrm{pH} 6.0$ and 7.0 are shown for other mAbs in Supplemental Figs. 1-5. Max, maximum.

strong correlations with $R^{2}=0.99$, but, as expected, the data were severely undersampled and overfit, resulting in large S.E. values in parameter coefficients. To determine which subset of coefficients would yield the best correlation with half-life and clearance, LASSO regression was applied to reduce the number of predictors by introducing the regularization parameter $\lambda$ (Tibshirani, 1996, 2011). Applying LASSO to the tabulated mAb parameters revealed different solutions to the regression problem depending on the value of $\lambda$. As the value of $\lambda$ was increased, the number of nonzero coefficients decreased while the mean squared error increased (Fig. 4). Based on this analysis, the best single parameter for half-life prediction was FcRn response at $\mathrm{pH} 7.0$ (consistent with the high $R^{2}$ value for this individual correlation). Examining solutions for lower values of $\lambda$ revealed that the combination of two parameters most strongly associated with half-life was $\mathrm{FcRn}$ response at $\mathrm{pH} 7.0$ and $\Delta \mathrm{C}_{\mathrm{P}}$. These same two parameters were also the best combination of

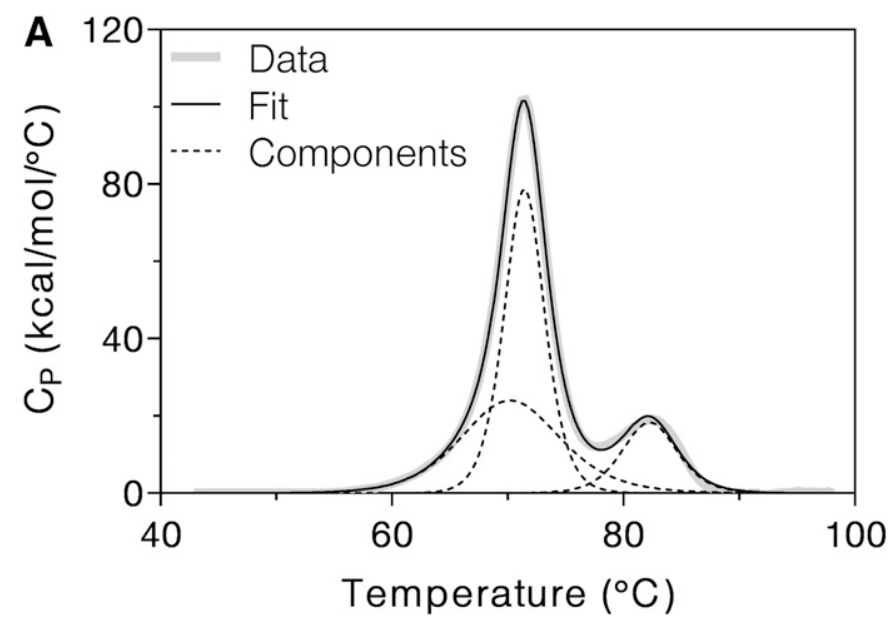

B

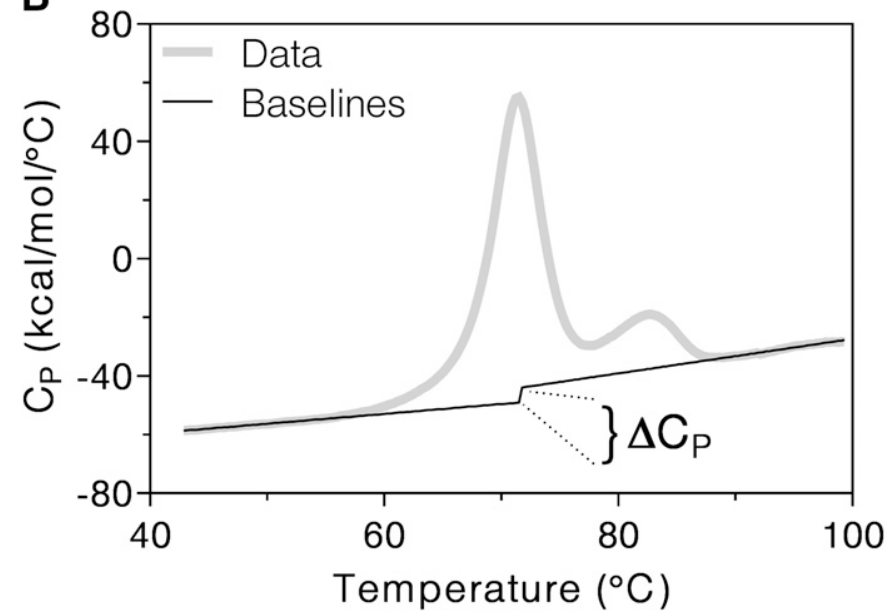

Fig. 2. DSC thermograms showing the unfolding of bevacizumab at $\mathrm{pH}$ 7.2. (A) After performing "Progress Baseline" subtraction, the data were fit to a threecomponent, non-two-state model to extract the $\Delta \mathrm{H}$ and $\mathrm{T}_{\mathrm{m}}$ associated with three unfolding events. Data are shown as a thick gray line, the fit is shown as a narrow black line, and the fitted components are shown as black dotted lines. (B) Baselines of the folded and unfolded states were fit using the "Step at Half Area" baseline option. The difference in $\mathrm{C}_{\mathrm{P}}$ at half area was calculated as the $\Delta \mathrm{C}_{\mathrm{P}}$. Replicates, peak fits, and baseline fits are shown for all mAbs in Supplemental Figs. 6-8.

clearance determinants, though in the opposite order of importance. To ensure that this analysis was not discounting the $\mathrm{pH} 6.0$ binding data because it was represented by two distinct parameters, LASSO regression was also performed using the maximum response at $\mathrm{pH} 6.0$ instead of both $\mathrm{k}_{\mathrm{a}}$ and $\mathrm{k}_{\mathrm{d}}$. This five-parameter regression yielded results similar to those of the original six-parameter solution: response at $\mathrm{pH} 7.0$ and $\Delta \mathrm{C}_{\mathrm{P}}$ remained the top pair of predictors for both half-life and clearance (Supplemental Fig. 9).

Next, normal multiple regression was performed using FcRn response at $\mathrm{pH} 7.0$ and $\Delta \mathrm{C}_{\mathrm{P}}$ as the only two predictors for half-life. This was done to determine best-fit coefficients for the parameters without applying any penalty function for the number of parameters. The resulting correlation between the linear combination of these two parameters and half-life or clearance was much stronger than the correlation for each individual parameter $\left(R^{2}=0.91\right.$ and $R^{2}=0.96$, respectively, Fig. 5, A and $\left.\mathrm{B}\right)$. Because the parameter matrix was normalized to have a mean of 0 and an S.D. of 1 prior to analysis, any differences in the magnitude or range of parameters were eliminated. In other words, regression results will depend on relative differences rather than on absolute values of biophysical parameters. Thus, the regression coefficients reflect the 

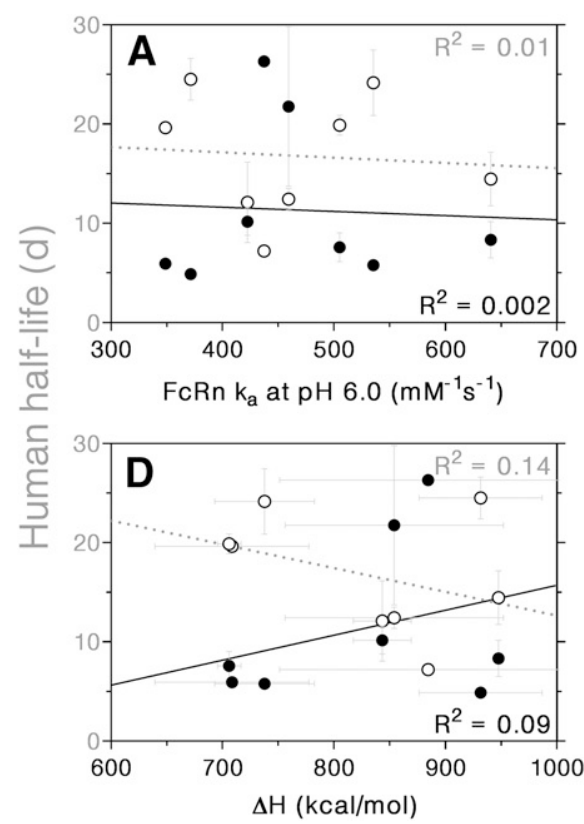
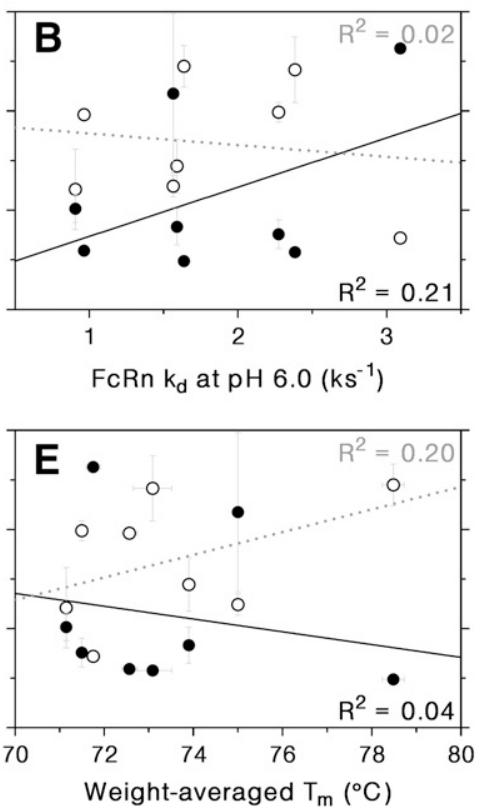
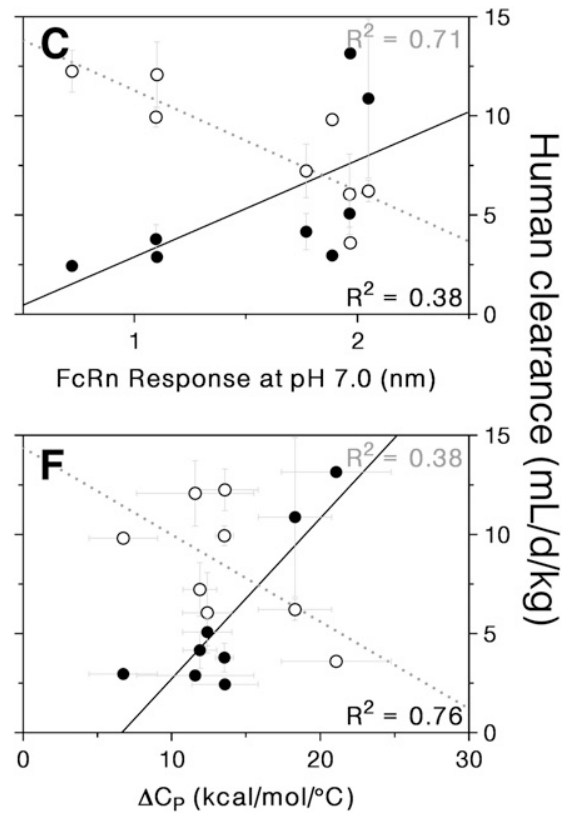

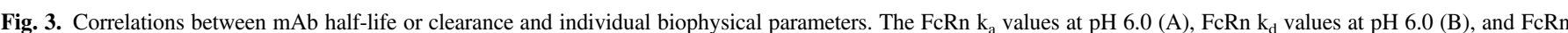

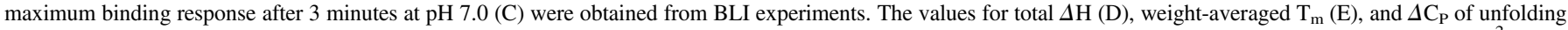

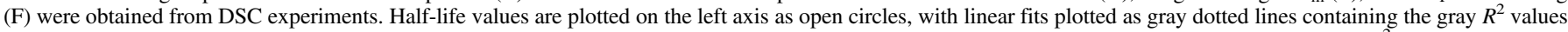

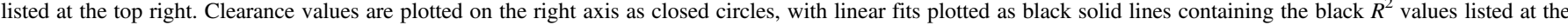
bottom right.

relative importance of each parameter for half-life or clearance prediction. In this case, the half-life coefficient for $\mathrm{pH} 7.0$ response was $-4.63 \pm 0.83$, and for $\Delta \mathrm{C}_{\mathrm{P}}$ was $-2.88 \pm 0.83$ with an intercept of $16.8 \pm 0.8$. In other words, both $\mathrm{pH} 7.0$ response and $\Delta \mathrm{C}_{\mathrm{P}}$ were negatively correlated with half-life, but $\mathrm{pH} 7.0$ response was somewhat more important for the two-parameter correlation. For clearance, $\Delta \mathrm{C}_{\mathrm{P}}$ was the more important of the two determinants. The $\mathrm{pH} 7.0$ response coefficient was $1.86 \pm 0.35$, the $\Delta \mathrm{C}_{\mathrm{P}}$ coefficient was $3.15 \pm 0.35$, and the intercept was $5.67 \pm 0.32$.

To test the robustness of the two-parameter correlation and assess its predictive power, we performed leave-one-out (also called "jackknife") subsampling: the half-life and clearance of each $\mathrm{mAb}$ were predicted based on the measured biophysical parameters of the mAb and a regression model trained on the other seven mAbs. When LASSO analysis was performed for each subset of mAbs, all but one subset yielded $\mathrm{pH} 7.0$ response and $\Delta \mathrm{C}_{\mathrm{P}}$ as the primary two determinants for both half-life and clearance. When omalizumab was excluded, these two parameters were most important for clearance; but for half-life, $\mathrm{pH} 7.0$ response, $\Delta \mathrm{H}$, and $\Delta \mathrm{C}_{\mathrm{P}}$ were the first three determinants. Despite this single exception, for consistency, the $\mathrm{pH} 7.0$ response and $\Delta \mathrm{C}_{\mathrm{P}}$ of each $\mathrm{mAb}$ were used to predict its half-life and clearance. The values of the regression intercept and coefficients were similar when any one of the mAbs was omitted from the correlations (Table 2). Indeed, the S.D. for the intercept, the $\mathrm{pH} 7.0$ response coefficient, and the $\Delta \mathrm{C}_{\mathrm{P}}$ coefficient from subsampling analysis were all under $16 \%$ for both half-life and clearance.

The prediction of $\mathrm{mAb}$ half-life based on its $\mathrm{pH} 7.0$ response and $\Delta \mathrm{C}_{\mathrm{P}}$ was fairly accurate, with differences between measured and predicted half-lives ranging from 0 to 4.7 days $(0 \%-38 \%)$ and a RMSD of 2.7 days (16\%). Comparing the leave-one-out twoparameter predicted half-life of an mAb to the reported value resulted in a correlation of $R^{2}=0.79$ (Fig. $5 \mathrm{C}$ ). Analogous prediction of $\mathrm{mAb}$ clearance based on the same two parameters resulted in an RMSD of $1.4 \mathrm{ml} /$ day per kilogram (24\%). In this case, the correlation between predicted and reported clearance indicated strong predictive power $\left(R^{2}=0.88\right)$ (Fig. 5D).

\section{Discussion}

The half-life of a therapeutic $\mathrm{mAb}$ is a vital biologic characteristic that determines how frequently the drug must be administered. In many cases, it is desirable to invest in mAbs that have slow elimination kinetics, so they can be administered at a lower dose or reduced frequency, ultimately saving time and money for both patients and companies. Despite the incentive for characterizing $\mathrm{mAb}$ half-life early in the drug pipeline, it has been difficult to predict the PK properties of mAbs before they enter human trials. Many individual parameters, including biologic properties like FcRn affinity or glycosylation state, biophysical properties like nonspecific binding or aggregation propensity, and sequence-based properties like allotype, have been correlated to half-life with varying degrees of interdependence (Wang et al., 2011; Datta-Mannan et al., 2015a; Ternant et al., 2016; Tibbitts et al., 2016). It appears that no single property of an $\mathrm{mAb}$ can be used to accurately predict $\mathrm{PK}$ properties. At the same time, it would be advantageous to know the smallest, most tractable set of parameters that would be predictively useful. Thus, we took a combinatorial approach to determine whether half-life prediction could be improved using multiple parameters incorporated into a cohesive model. The LASSO machine-learning approach provides a statistically rigorous method to identify parameter combinations that best predict outcomes.

In forming a panel of mAbs to analyze, various factors were considered. The primary goal was to obtain a small sample of mAbs with a large spread of human half-life values based on published clinical data. Thus, mAbs were selected with half-lives ranging from 1 week to over 3 weeks. Because the subtype of $\operatorname{IgG}$ heavy chain is known to affect mAb PK, with IgG3 having a shorter serum half-life than other subtypes, only IgG1 mAbs were considered for analysis 


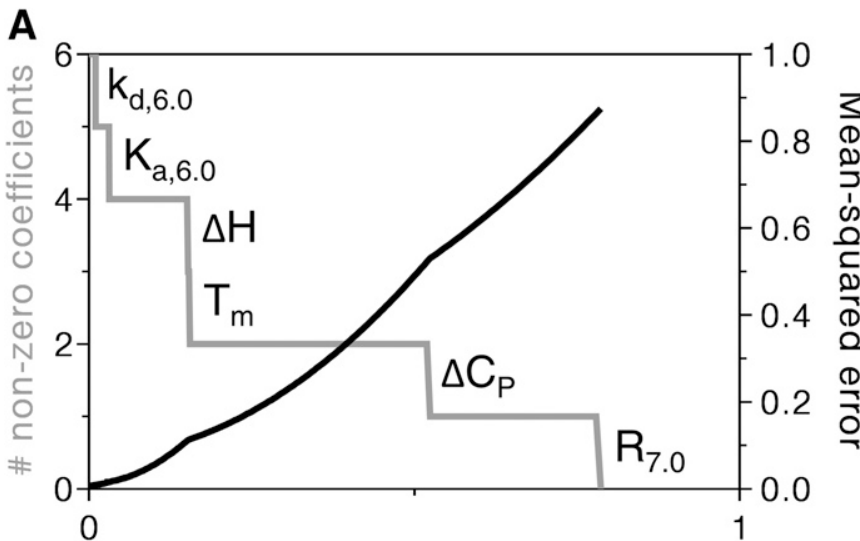

$\lambda$

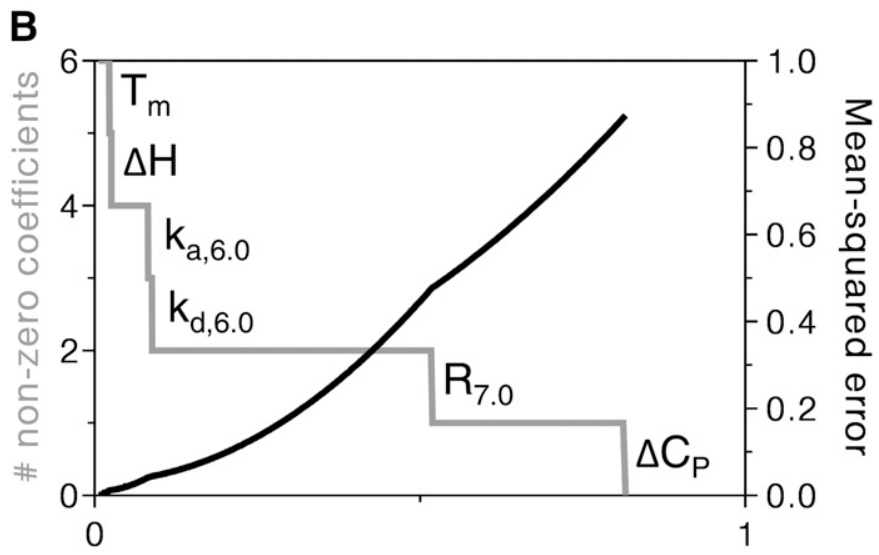

$\lambda$

Fig. 4. LASSO analysis to determine the most important predictors of mAb half-life (A) and clearance (B). As the value of the regularization parameter $\lambda$ increased, the number of nonzero coefficients (gray line, left axis) decreased while the mean squared error (black line, right axis) increased. The most important parameters for multiple regression of half-life (introduced at the highest values of $\lambda$ ) were $\mathrm{pH} 7.0$ response $\left(\mathrm{R}_{7.0}\right), \Delta \mathrm{C}_{\mathrm{P}}$ of unfolding, weight-averaged $\mathrm{T}_{\mathrm{m}}$, total $\Delta \mathrm{H}$ of unfolding, $\mathrm{pH}$ $6.0 \mathrm{k}_{\mathrm{a}}\left(\mathrm{k}_{\mathrm{a}, 6.0}\right)$, and $\mathrm{pH} 6.0 \mathrm{k}_{\mathrm{d}}\left(\mathrm{k}_{\mathrm{d}, 6.0}\right)$, in that order. For clearance, the order of importance was $\Delta \mathrm{C}_{\mathrm{P}}, \mathrm{R}_{7.0}, \mathrm{k}_{\mathrm{d}, 6.0}, \mathrm{k}_{\mathrm{a}, 6.0}, \Delta \mathrm{H}$, and $\mathrm{T}_{\mathrm{m}}$.

(Stapleton et al., 2011). Likewise, all the selected mAbs contained $\kappa$-light chains. Only mAbs that target soluble antigens were selected, to minimize differences in half-life that occur as a result of receptormediated disposition or other target-dependent processes and to emphasize intrinsic biophysical parameters. Of course, it was not possible to eliminate every source of variation with the relatively small number of mAbs available to us. The panel contains mAbs that are chimeric, humanized, or fully human, and allotypes $\mathrm{m} 3,1 ; \mathrm{m} 17,1$; and $m 17,-1$ are all represented. However, neither framework nor allotype were associated with significant differences in half-life or clearance (Supplemental Fig. 10).

The FcRn binding data at $\mathrm{pH} 6.0$ yielded higher affinities than some reports in the literature, due to the level of FcRn immobilized and the bivalent mechanism of FcRn-IgG binding (Suzuki et al., 2010; Wang et al., 2011). Nevertheless, the data within this experiment are directly comparable and revealed modest differences in association and dissociation rates that were not correlated with half-life. As the FcRn binding interface of these mAbs is identical, it is possible that the observed differences in FcRn binding are caused by charge-mediated Fab-FcRn interactions (Schoch et al., 2015). Previous studies have noted that stronger FcRn binding at endosomal $\mathrm{pH}$ leads to enhanced
IgG half-life (Dall'Acqua et al., 2006; Hinton et al., 2006; Zalevsky et al., 2010). It should be noted that these studies compare the clearance of a given $\mathrm{mAb}$ with and without mutations that affect FcRn binding. The variable regions of the $\mathrm{mAb}$ are conserved, and the biophysical properties of the mutants are expected to be similar. Localization of mutations to the FcRn binding site creates large (10to 30-fold) increases in FcRn affinity that are much larger than the 3 -fold span in affinity observed here. In these cases, it makes sense that FcRn binding would be a primary determinant of half-life. Other studies have shown that FcRn binding at $\mathrm{pH} 6$ is not strongly associated with half-life when distinct clinical mAbs are examined, or even when the variable regions are maintained (Dall'Acqua et al., 2002; Gurbaxani et al., 2006; Wang et al., 2011; Datta-Mannan et al., 2012).

The ability of mAbs to bind FcRn at pH 7.0, however, was strikingly related to their half-lives in humans. Although it was not possible to reliably extract $\mathrm{k}_{\mathrm{a}}$ and $\mathrm{k}_{\mathrm{d}}$ values at $\mathrm{pH} 7$, the maximum response achieved at the highest mAb concentration provided an objective measure of binding that was negatively correlated with half-life. As the mass and concentration of mAbs were effectively equal and the association times were identical, the response parameter provides an unbiased measure of FcRn binding. The inverse correlation between neutral $\mathrm{pH}$ binding and half-life has been observed previously by groups showing that weak FcRn binding at neutral $\mathrm{pH}$ is just as important as tight binding in the endosome (Wang et al., 2011; Borrok et al., 2015). The observation that excessive binding at neutral $\mathrm{pH}$ accelerates clearance may be due to FcRn-dependent endocytosis and degradation or FcRn-independent processes related to nonspecific binding. The inability to globally fit the $\mathrm{pH} 7$ data, although inconvenient, may suggest the presence of multiple conformations or protonation states of the $\mathrm{Fc}$ or FcRn at this $\mathrm{pH}$, or of polyvalent interactions, which complicates simple 1:1 fits.

It is reasonable that the serum stability of an mAb would be related to its inherent thermal stability. Molecules containing unstable variable regions may be more prone to unfold or aggregate. Both processes would be expected to accelerate clearance, either due to the generation of an immune response or the loss of FcRn binding capacity (Ratanji et al., 2014; Roberts, 2014). This hypothesis is supported by DSC data showing a weak but positive correlation between weight-averaged $\mathrm{T}_{\mathrm{m}}$ and half-life. Interestingly, the correlation for $\Delta \mathrm{C}_{\mathrm{P}}$ and half-life was negative, suggesting that $\mathrm{mAbs}$ containing more buried hydrophobic residues are more likely to have shorter half-lives. Indeed, $\Delta \mathrm{C}_{\mathrm{P}}$ was moderately positively correlated with the grand average of hydropathy (GRAVY) score $\left(R^{2}=0.33\right)$ (Supplemental Fig. 11) based on the amino acid sequence of the mAb variable regions (Kyte and Doolittle, 1982). An abundance of buried hydrophobic residues can stabilize the folded state in buffer, but may introduce opportunities for aggregation and other nonspecific interactions in the presence of other proteins or tissue constituents. Thus, the biologic matrix could actually destabilize the monomeric folded state if nonspecific, hydrophobically driven interactions pull the equilibrium toward unfolding or aggregation with serum components. Although previous efforts have examined less direct measures of stability such as nonspecific binding or selfassociation (Avery et al., 2018), our use of DSC enables the delineation of the precise thermodynamic parameters that provide the most predictive value.

A challenge associated with half-life prediction is how to account for the effects of multiple determinants without overparameterizing the model. Here, LASSO was used to identify the most powerful combination of two biophysical parameters for half-life and clearance prediction. The advantage of using LASSO was the ability to explore all possible combinations of parameters and to vary the value of $\lambda$ so 

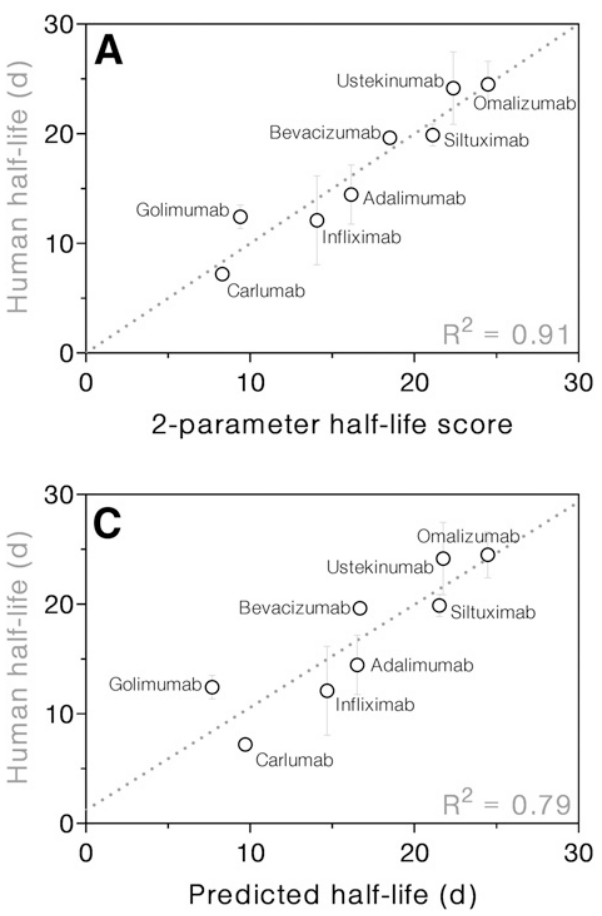
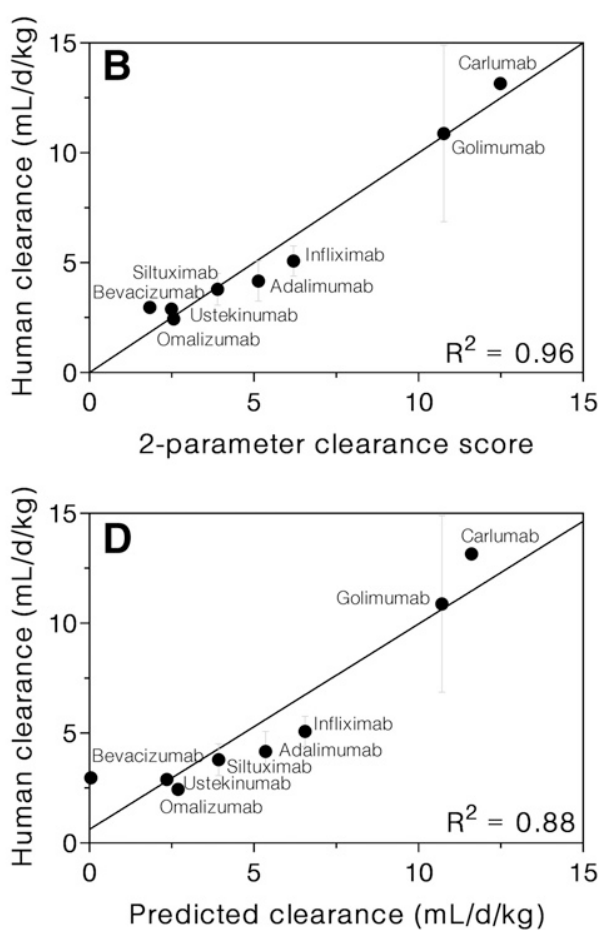

Fig. 5. mAb half-life (A) and clearance (B) correlated strongly with the respective twoparameter scores, which are based on the FcRn response at $\mathrm{pH} 7.0$ and $\Delta \mathrm{C}_{\mathrm{P}}$. Half-life $(\mathrm{C})$ and clearance (D) predictions were validated using leave-one-out analysis. Multiple regression was performed using response at $\mathrm{pH} 7.0$ and $\Delta \mathrm{C}_{\mathrm{P}}$ as predictors. Each $\mathrm{mAb}$ in turn was omitted from the regression, and then its values of $\mathrm{pH}$ 7 response and $\Delta \mathrm{C}_{\mathrm{P}}$ were used to predict its half-life or clearance using the regression results of the remaining seven mAbs. that the number of nonzero coefficients ranged from 0 to 6 . In this way, the response at $\mathrm{pH} 7.0$ and the $\Delta \mathrm{C}_{\mathrm{P}}$ were identified as the two parameters that, in combination, yielded the best correlation to both halflife and clearance. Thus, accounting for both FcRn binding at neutral $\mathrm{pH}$ and thermodynamic stability allows for the most accurate prediction of $\mathrm{mAb}$ PK.

The approach taken here was fundamentally empirical in nature and designed more to generate hypotheses than to test them. Experiments were devised to allow for the extraction of biophysical parameters that may be associated with mAb serum stability. Although the limited set of predictors selected for analysis was guided by current knowledge of mAb PK, the analysis was not biased by our current mechanistic understanding of $\mathrm{mAb}$ recycling and clearance. This approach is therefore useful for generating new hypotheses about the phenomenon of interest. In this case, analysis identified $\mathrm{pH} 7$ response and $\Delta \mathrm{C}_{\mathrm{P}}$ as predictors that are inversely correlated with half-life and positively correlated with clearance. Although the importance of FcRn release at neutral $\mathrm{pH}$ has been demonstrated, we did not encounter any previous reports that low $\Delta \mathrm{C}_{\mathrm{P}}$ values contribute to long $\mathrm{mAb}$ half-life. Perhaps the relationship between $\Delta \mathrm{C}_{\mathrm{P}}$ and clearance can be further explored to clarify the mechanism behind this observation.

Importantly, the parameters we considered by no means encompass all the factors that could affect the disposition of a particular mAb. A number of additional biophysical properties, reflective of protein stability, nonspecific binding, and aggregation propensity, have been advanced as important predictive metrics of PK and pharmacodynamics (Tibbitts et al., 2016; Jain et al., 2017). Expanding the use of LASSO and similar regression analyses to larger datasets, covering more samples and including more biophysical parameters, could prove informative, particularly in clarifying which in vitro parameters should be emphasized. Empirical, combinatorial approaches such as the one developed here could be generally useful for many different mAb-based therapeutics or for non-mAb therapeutics whose PK can be predicted by other combinations of biophysical determinants.

TABLE 2

Prediction of $\mathrm{mAb}$ half-life and clearance using leave-one-out regression

\begin{tabular}{|c|c|c|c|c|c|c|}
\hline \multirow{2}{*}{ Antibody Omitted and Predicted } & \multicolumn{3}{|c|}{ Half-Life Prediction } & \multicolumn{3}{|c|}{ Clearance Prediction } \\
\hline & Intercept & FcRn Response, pH 7.0 Coefficient & $\Delta \mathrm{C}_{\mathrm{P}}$ Coefficient & Intercept & FcRn Response, pH 7.0 Coefficient & $\Delta \mathrm{C}_{\mathrm{P}}$ Coefficient \\
\hline Adalimumab & $17.1 \pm 0.8$ & $-4.48 \pm 0.87$ & $-3.03 \pm 0.87$ & $5.82 \pm 0.33$ & $1.94 \pm 0.34$ & $3.07 \pm 0.34$ \\
\hline Bevacizumab & $16.4 \pm 0.9$ & $-5.04 \pm 0.99$ & $-2.13 \pm 1.25$ & $5.31 \pm 0.19$ & $1.45 \pm 0.20$ & $3.90 \pm 0.26$ \\
\hline Carlumab & $17.1 \pm 0.9$ & $-4.47 \pm 0.90$ & $-2.31 \pm 1.17$ & $5.48 \pm 0.35$ & $1.76 \pm 0.35$ & $2.80 \pm 0.46$ \\
\hline Golimumab & $16.2 \pm 0.6$ & $-5.13 \pm 0.60$ & $-3.50 \pm 0.62$ & $5.65 \pm 0.39$ & $1.84 \pm 0.41$ & $3.13 \pm 0.43$ \\
\hline Infliximab & $17.1 \pm 0.8$ & $-4.31 \pm 0.87$ & $-3.05 \pm 0.83$ & $5.86 \pm 0.30$ & $2.04 \pm 0.32$ & $3.06 \pm 0.31$ \\
\hline Omalizumab & $16.8 \pm 1.0$ & $-4.62 \pm 1.26$ & $-2.89 \pm 0.94$ & $5.71 \pm 0.40$ & $1.80 \pm 0.53$ & $3.17 \pm 0.40$ \\
\hline Siltuximab & $17.0 \pm 0.9$ & $-4.85 \pm 0.96$ & $-2.84 \pm 0.89$ & $5.69 \pm 0.39$ & $1.84 \pm 0.42$ & $3.16 \pm 0.39$ \\
\hline Ustekinumab & $16.5 \pm 0.8$ & $-4.34 \pm 0.89$ & $-2.78 \pm 0.84$ & $5.61 \pm 0.38$ & $1.93 \pm 0.41$ & $3.18 \pm 0.38$ \\
\hline Average & $16.8 \pm 0.4$ & $-4.66 \pm 0.32$ & $-2.82 \pm 0.43$ & $5.64 \pm 0.18$ & $1.83 \pm 0.18$ & $3.18 \pm 0.31$ \\
\hline (None omitted) & $16.8 \pm 0.8$ & $-4.63 \pm 0.83$ & $-2.88 \pm 0.83$ & $5.67 \pm 0.32$ & $1.86 \pm 0.35$ & $3.15 \pm 0.35$ \\
\hline
\end{tabular}




\section{Acknowledgments}

DSC experiments were performed at the Analytical Biopharmacy Core facility of the University of Washington. We thank John Sumida for assistance with DSC instrumentation and software.

\section{Authorship Contributions}

Participated in research design: Goulet, Tam, Chiu, Atkins, and Nath.

Conducted experiments: Goulet and Watson.

Contributed new reagents or analytic tools: Tam and Zwolak.

Performed data analysis: Goulet.

Wrote or contributed to the writing of the manuscript: Goulet, Watson, Tam, Zwolak, Chiu, Atkins, and Nath.

\section{References}

Abdiche YN, Yeung YA, Chaparro-Riggers J, Barman I, Strop P, Chin SM, Pham A, Bolton G, McDonough D, Lindquist K, et al. (2015) The neonatal Fc receptor $(\mathrm{FcRn})$ binds independently to both sites of the IgG homodimer with identical affinity. MAbs 7:331-343.

Avery LB, Wade J, Wang M, Tam A, King A, Piche-Nicholas N, Kavosi MS, Penn S, Cirelli D, Kurz JC, et al. (2018) Establishing in vitro in vivo correlations to screen monoclonal antibodies for physicochemical properties related to favorable human pharmacokinetics. MAbs 10:244-255.

Beck A, Goetsch L, Dumontet C, and Corvaïa N (2017) Strategies and challenges for the next generation of antibody-drug conjugates. Nat Rev Drug Discov 16:315-337.

Borrok MJ, Wu Y, Beyaz N, Yu X-Q, Oganesyan V, Dall'Acqua WF, and Tsui P (2015) pHdependent binding engineering reveals an $\mathrm{FcRn}$ affinity threshold that governs IgG recycling. $J$ Biol Chem 290:4282-4290.

Cornillie F, Shealy D, D'Haens G, Geboes K, Van Assche G, Ceuppens J, Wagner C, Schaible T, Plevy SE, Targan SR, et al. (2001) Infliximab induces potent anti-inflammatory and local immunomodulatory activity but no systemic immune suppression in patients with Crohn's disease. Aliment Pharmacol Ther 15:463-473.

Dall'Acqua WF, Kiener PA, and Wu H (2006) Properties of human IgG1s engineered for enhanced binding to the neonatal Fc receptor (FcRn). J Biol Chem 281:23514-23524.

Dall'Acqua WF, Woods RM, Ward ES, Palaszynski SR, Patel NK, Brewah YA, Wu H, Kiener PA, and Langermann S (2002) Increasing the affinity of a human IgG1 for the neonatal Fc receptor: biological consequences. J Immunol 169:5171-5180.

Datta-Mannan A, Chow CK, Dickinson C, Driver D, Lu J, Witcher DR, and Wroblewski VJ (2012) FcRn affinity-pharmacokinetic relationship of five human IgG4 antibodies engineered for improved in vitro FcRn binding properties in cynomolgus monkeys. Drug Metab Dispos 40:1545-1555.

Datta-Mannan A, Lu J, Witcher DR, Leung D, Tang Y, and Wroblewski VJ (2015a) The interplay of non-specific binding, target-mediated clearance and FcRn interactions on the pharmacokinetics of humanized antibodies. MAbs 7:1084-1093

Datta-Mannan A, Thangaraju A, Leung D, Tang Y, Witcher DR, Lu J, and Wroblewski VJ (2015b) Balancing charge in the complementarity-determining regions of humanized $\mathrm{mAbs}$ without affecting pI reduces non-specific binding and improves the pharmacokinetics. MAbs 7:483-493.

den Broeder A, van de Putte L, Rau R, Schattenkirchner M, Van Riel P, Sander O, Binder C, Fenner H, Bankmann Y, Velagapudi R, et al. (2002) A single dose, placebo controlled study of the fully human anti-tumor necrosis factor-alpha antibody adalimumab (D2E7) in patients with rheumatoid arthritis. J Rheumatol 29:2288-2298.

Dostalek M, Prueksaritanont T, and Kelley RF (2017) Pharmacokinetic de-risking tools for selection of monoclonal antibody lead candidates. MAbs 9:756-766.

Dotan I, Ron Y, Yanai H, Becker S, Fishman S, Yahav L, Ben Yehoyada M, and Mould DR (2014) Patient factors that increase infliximab clearance and shorten half-life in inflammatory bowel disease: a population pharmacokinetic study. Inflamm Bowel Dis 20:2247-2259.

Fasanmade AA, Adedokun OJ, Blank M, Zhou H, and Davis HM (2011) Pharmacokinetic properties of infliximab in children and adults with Crohn's disease: a retrospective analysis of data from 2 phase III clinical trials. Clin Ther 33:946-964.

Gurbaxani B, Dela Cruz LL, Chintalacharuvu K, and Morrison SL (2006) Analysis of a family of antibodies with different half-lives in mice fails to find a correlation between affinity for FcRn and serum half-life. Mol Immunol 43:1462-1473.

Han K, Peyret T, Marchand M, Quartino A, Gosselin NH, Girish S, Allison DE, and Jin J (2016) Population pharmacokinetics of bevacizumab in cancer patients with external validation. Cancer Chemother Pharmacol 78:341-351.

Hayashi N, Tsukamoto Y, Sallas WM, and Lowe PJ (2007) A mechanism-based binding model for the population pharmacokinetics and pharmacodynamics of omalizumab. Br J Clin Pharmaco 63:548-561.

Hinton PR, Xiong JM, Johlfs MG, Tang MT, Keller S, and Tsurushita N (2006) An engineered human IgG1 antibody with longer serum half-life. J Immunol 176:346-356.

Jain T, Sun T, Durand S, Hall A, Houston NR, Nett JH, Sharkey B, Bobrowicz B, Caffry I, Yu Y et al. (2017) Biophysical properties of the clinical-stage antibody landscape. Proc Natl Acad Sci USA 114:944-949.

Kaplon H and Reichert JM (2018) Antibodies to watch in 2018. MAbs 10:183-203.

Kurzrock R, Voorhees PM, Casper C, Furman RR, Fayad L, Lonial S, Borghaei H, Jagannath S, Sokol L, Usmani SZ, et al. (2013) A phase I, open-label study of siltuximab, an anti-IL-6 monoclonal antibody, in patients with B-cell non-Hodgkin lymphoma, multiple myeloma, or Castleman disease. Clin Cancer Res 19:3659-3670.

Kyte J and Doolittle RF (1982) A simple method for displaying the hydropathic character of a protein. J Mol Biol 157:105-132.

Li J, Gupta M, Jin D, Xin Y, Visich J, and Allison DE (2013) Characterization of the long-term pharmacokinetics of bevacizumab following last dose in patients with resected stage II and III carcinoma of the colon. Cancer Chemother Pharmacol 71:575-580.

Ling J, Lyn S, Xu Z, Achira M, Bouman-Thio E, Shishido A, Ford J, Shankar G, Wagner C, Kim KT, et al. (2010) Lack of racial differences in the pharmacokinetics of subcutaneous golimumab in healthy Japanese and Caucasian male subjects. J Clin Pharmacol 50:792-802.

Lu J-F, Bruno R, Eppler S, Novotny W, Lum B, and Gaudreault J (2008) Clinical pharmacokinetics of bevacizumab in patients with solid tumors. Cancer Chemother Pharmacol 62:779-786.
Majumdar R, Esfandiary R, Bishop SM, Samra HS, Middaugh CR, Volkin DB, and Weis DD (2015) Correlations between changes in conformational dynamics and physical stability in a mutant IgG1 mAb engineered for extended serum half-life. MAbs 7:84-95.

Raghavan M, Bonagura VR, Morrison SL, and Bjorkman PJ (1995) Analysis of the pH dependence of the neonatal $\mathrm{Fc}$ receptor/immunoglobulin $\mathrm{G}$ interaction using antibody and receptor variants. Biochemistry 34:14649-14657.

Ratanji KD, Derrick JP, Dearman RJ, and Kimber I (2014) Immunogenicity of therapeutic proteins: influence of aggregation. J Immunotoxicol 11:99-109.

Robbie GJ, Criste R, Dall'acqua WF, Jensen K, Patel NK, Losonsky GA, and Griffin MP (2013) A novel investigational Fc-modified humanized monoclonal antibody, motavizumab-YTE, has an extended half-life in healthy adults. Antimicrob Agents Chemother 57:6147-6153.

Roberts CJ (2014) Therapeutic protein aggregation: mechanisms, design, and control. Trend Biotechnol 32:372-380.

Roopenian DC and Akilesh S (2007) FcRn: the neonatal Fc receptor comes of age. Nat Rev Immunol 7:715-725.

Roopenian DC, Christianson GJ, Sproule TJ, Brown AC, Akilesh S, Jung N, Petkova S, Avanessian L, Choi EY, Shaffer DJ, et al. (2003) The MHC class I-like IgG receptor controls perinatal IgG transport, IgG homeostasis, and fate of IgG-Fc-coupled drugs. J Immunol 170:3528-3533.

Sandhu SK, Papadopoulos K, Fong PC, Patnaik A, Messiou C, Olmos D, Wang G, Tromp BJ, Puchalski TA, Balkwill F, et al. (2013) A first-in-human, first-in-class, phase I study of carlumab (CNTO 888), a human monoclonal antibody against CC-chemokine ligand 2 in patients with solid tumors. Cancer Chemother Pharmacol 71:1041-1050.

Schoch A, Kettenberger H, Mundigl O, Winter G, Engert J, Heinrich J, and Emrich T (2015) Charge-mediated influence of the antibody variable domain on FcRn-dependent pharmacokinetics. Proc Natl Acad Sci USA 112:5997-6002.

Souders CA, Nelson SC, Wang Y, Crowley AR, Klempner MS, and Thomas W Jr (2015) A novel in vitro assay to predict neonatal $\mathrm{Fc}$ receptor-mediated human IgG half-life. MAbs 7:912-921.

Spiess C, Zhai Q, and Carter PJ (2015) Alternative molecular formats and therapeutic applications for bispecific antibodies. Mol Immunol 67 (2 Pt A):95-106.

Stapleton NM, Andersen JT, Stemering AM, Bjarnarson SP, Verheul RC, Gerritsen J, Zhao Y, Kleijer M, Sandlie I, de Haas M, Jonsdottir I, van der Schoot CE, and Vidarsson G (2011) Competition for FcRn-mediated transport gives rise to short half-life of human IgG3 and offers therapeutic potential. Nat Comm 2 (599):1-9.

Suzuki T, Ishii-Watabe A, Tada M, Kobayashi T, Kanayasu-Toyoda T, Kawanishi T, and Yamaguchi $T$ (2010) Importance of neonatal FcR in regulating the serum half-life of therapeutic proteins containing the $\mathrm{Fc}$ domain of human IgG1: a comparative study of the affinity of monoclonal antibodies and Fc-fusion proteins to human neonatal FcR. J Immunol 184:1968-1976. Tam SH, McCarthy SG, Brosnan K, Goldberg KM, and Scallon BJ (2013) Correlations between pharmacokinetics of $\mathrm{IgG}$ antibodies in primates vs. $\mathrm{FcRn}$-transgenic mice reveal a rodent model with predictive capabilities. MAbs 5:397-405.

Ternant D, Arnoult C, Pugnière M, Dhommée C, Drocourt D, Perouzel E, Passot C, Baroukh N, Mulleman D, Tiraby G, et al. (2016) IgG1 allotypes influence the pharmacokinetics of therapeutic monoclonal antibodies through FcRn binding. J Immunol 196:607-613.

Ternant D, Aubourg A, Magdelaine-Beuzelin C, Degenne D, Watier H, Picon L, and Paintaud G (2008) Infliximab pharmacokinetics in inflammatory bowel disease patients. Ther Drug Monit 30:523-529.

Tibshirani R (1996) Regression selection and shrinkage via the lasso. J R Stat Soc B 58:267-288. Tibshirani R (2011) Regression shrinkage and selection via the lasso: a retrospective. J R Stat Soc B 73:273-282

Tibbitts J, Canter D, Graff R, Smith A, and Khawli LA (2016) Key factors influencing ADME properties of therapeutic proteins: a need for ADME characterization in drug discovery and development. MAbs 8:229-245.

Wang W, Lu P, Fang Y, Hamuro L, Pittman T, Carr B, Hochman J, and Prueksaritanont T (2011) Monoclonal antibodies with identical Fc sequences can bind to FcRn differentially with pharmacokinetic consequences. Drug Metab Dispos 39:1469-1477.

Wang W, Wang EQ, and Balthasar JP (2008) Monoclonal antibody pharmacokinetics and pharmacodynamics. Clin Pharmacol Ther 84:548-558.

Weisman MH, Moreland LW, Furst DE, Weinblatt ME, Keystone EC, Paulus HE, Teoh LS, Velagapudi RB, Noertersheuser PA, Granneman GR, et al. (2003) Efficacy, pharmacokinetic, and safety assessment of adalimumab, a fully human anti-tumor necrosis factor-alpha monoclonal antibody, in adults with rheumatoid arthritis receiving concomitant methotrexate: a pilot study. Clin Ther 25:1700-1721.

Xu Z, Wang Q, Zhuang Y, Frederick B, Yan H, Bouman-Thio E, Marini JC, Keen M, Snead D, Davis HM, et al. (2010) Subcutaneous bioavailability of golimumab at 3 different injection sites in healthy subjects. $J$ Clin Pharmacol 50:276-284.

Zalevsky J, Chamberlain AK, Horton HM, Karki S, Leung IWL, Sproule TJ, Lazar GA, Roopenian DC, and Desjarlais JR (2010) Enhanced antibody half-life improves in vivo activity. Nat Biotechnol 28:157-159.

Zhou H, Jang H, Fleischmann RM, Bouman-Thio E, Xu Z, Marini JC, Pendley C, Jiao Q, Shankar G, Marciniak SJ, et al. (2007) Pharmacokinetics and safety of golimumab, a fully human antiTNF- $\alpha$ monoclonal antibody, in subjects with rheumatoid arthritis. J Clin Pharmacol 47:383-396 Zhu Y, Wang Q, Frederick B, Bouman-Thio E, Marini JC, Keen M, Petty KJ, Davis HM, and Zhou $\mathrm{H}$ (2013) Comparison of the pharmacokinetics of subcutaneous ustekinumab between Chinese and non-Chinese healthy male subjects across two phase 1 studies. Clin Drug Investig 33:291-301.

Zhuang Y, Lyn S, Lv Y, Xu Z, Bouman-Thio E, Masterson T, Ford JA, Keen M, Petty KJ, Davi HM, et al. (2013) Pharmacokinetics and safety of golimumab in healthy Chinese subjects following a single subcutaneous administration in a randomized phase I trial. Clin Drug Investig 33 795-800.

Zhuang Y, Xu Z, Frederick B, de Vries DE, Ford JA, Keen M, Doyle MK, Petty KJ, Davis HM, and Zhou H (2012) Golimumab pharmacokinetics after repeated subcutaneous and intravenous administrations in patients with rheumatoid arthritis and the effect of concomitant methotrexate: an open-label, randomized study. Clin Ther 34:77-90.

Address correspondence to: Abhinav Nath, Department of Medicinal Chemistry, University of Washington, Box 357610, Seattle, WA 98195-7610. E-mail: anath@ uw.edu; or William M. Atkins, Department of Medicinal Chemistry, University of Washington, Box 357610, Seattle, WA 98195-7610. E-mail: winky@uw.edu 